\section{Tritium Fuelled Experiments at JET}

Graph showing good agreement between measured and computer simulated emission rates of $14 \mathrm{MeV}$ neutrons for a JET discharge with a $11 \%$ tritium-deuterium mixture during the time of peak performance Ireprinted, with permission, from Nuclear Fusion 32 (1992) 187].

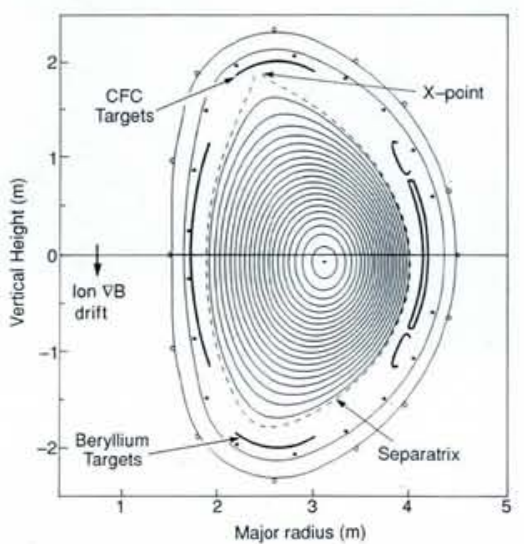

The magnetic configuration used for JET's $D-T$ experiments. The plasma contacts a continuous " $X$-point" carbon fibre composite (CFC) target on the wall of the vacuum vessel.

The Joint European Torus (JET) aims to study a plasma in conditions approaching

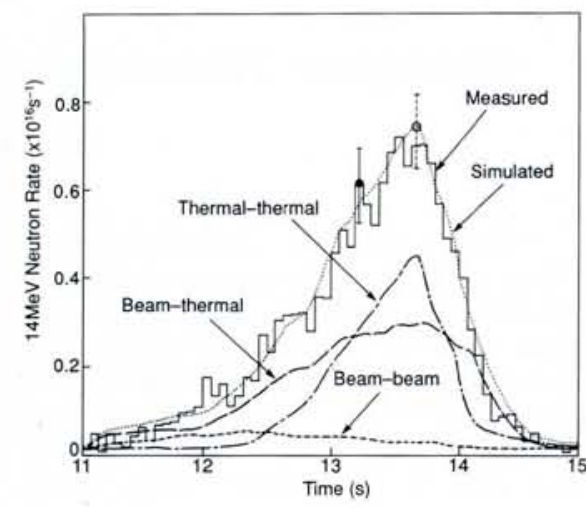

those needed for a thermonuclear reactor. Investigating the effects of $\alpha$-particles started with studies of energetic particles produced as fusion products or by cyclotron heating. In order to plan for full deuterium (D)-tritium (T) operation in 1996, these effects were addressed late last year by the first tokamak experiments ever undertaken using deuterium-tritium mixtures. Activation of the vessel to allow modification of the JET Torus in early 1992 was limited by restricting total neutron production to $<1.5 \times 10^{18}$ neutrons.

A recent publication by the JET Team [Nuclear Fusion 32 (1992) 187] describes the results of the tritium experiments. Earlier runs with deuterium plasma led to a particular magnetic configuration being chosen. This allowed a consistently higher energy input and a longer duration of the high performance phase of the discharge

\section{Physica
Scripta}

An international journal for experimental and theoretical physics

Vol. T40 1992

\section{Proceedings of the 23rd EGAS Conference}

\section{European Group for Atomic Spectroscopy - A Section of the EPS Division for Atomic and Molecular Physics}

Torún, Poland, 9-12 July 1991

Edited by: S. Legowski

About 168 physicists from 16 countries met to discuss problems of pure and applied atomic and molecular spectroscopy and related topics. Ten of the invited lectures are published in these Proceedings. These contributions are by B.E. Petley, D.N. Stacey, W. Ertmer, J. Helmcke et al., H.-A. Bachor and P.E. Clelland, T. Kühl, B.G. Wybourne, C. Bauche-Arnoult and J. Bauche, E.J. Krystautas and S.L. Bliman, and J. Zaremba.

80 pages in all

Orders to Physica Scripta at the address shown below;

Price: 150.- SEK or 30.- US\$

\section{Published by the}

ROYAL SWEDISH ACADEMY OF SCIENCES

Box 50005

S-10405 Stockholm / Sweden before "impurity bloom" set in (characterised by an increased emission of power from the plasma edge). Deuterium plasmas were heated by high power (mostly $\approx 11 \mathrm{MW}$ at $135 \mathrm{kV}$ and $\approx 2 \mathrm{MW}$ at $75 \mathrm{KV}$ ), long-duration deuterium neutral beams from 14 Positive Ion Neutral Injection (PINI) sources and fuelled also by up to two of these neutral beam (NB) sources injecting tritium gas. This is an important technical advance, being the first time a NB system has been used to inject energetic tritium neutrals at high power into a fusion plasma.

The $\mathrm{T}$ concentration was about $11 \%$ during peak performance for the best D-T discharge with $1 \% \mathrm{~T}$ in one PINI. As with the best of several similar high-performance $100 \% \mathrm{D}$ runs, there was good agreement between the measured neutron emission rates and those simulated using the TRANSP code (see figure). There was also good agreement for discharges using $100 \%$ T in two PINI's. TRANSP simulations can thus be used with some confidence to extrapolate the performance for the optimum fuel mix. Extrapolation of the best $100 \% \mathrm{D}$ experiment to this mix predicted a nominal fusion power amplification factor $Q_{\text {DT }}$ of 1.14 , so the total fusion power would have exceeded the total losses in an equivalent $D-T$ discharge in the same transient conditions.

One-third of the introduced tritium remained on the reactor walls, principally in wall tiles, after numerous 100\% D clean-up pulses spread over 15 weeks. The reactor vessel is now open for analysis and engineering work. 